\title{
A New Iterative Method for the Set of Solutions of Equilibrium Problems and of Operator Equations with Inverse-Strongly Monotone Mappings
}

\author{
Jong Kyu Kim, ${ }^{1}$ Nguyen Buong, ${ }^{2}$ and Jae Yull Sim ${ }^{3}$ \\ ${ }^{1}$ Department of Mathematics Education, Kyungnam University, Changwon 631-701, Republic of Korea \\ ${ }^{2}$ Vietnamese Academy of Science and Technology, Institute of Information Technology, 18 Hoang Quoc Viet, Cau Giay, Hanoi, Vietnam \\ ${ }^{3}$ Department of Mathematics, Kyungnam University, Changwon 631-701, Republic of Korea
}

Correspondence should be addressed to Jong Kyu Kim; jongkyuk@kyungnam.ac.kr

Received 25 April 2014; Accepted 27 May 2014; Published 16 June 2014

Academic Editor: Kyung Soo Kim

Copyright ( 2014 Jong Kyu Kim et al. This is an open access article distributed under the Creative Commons Attribution License, which permits unrestricted use, distribution, and reproduction in any medium, provided the original work is properly cited.

\begin{abstract}
The purpose of the paper is to present a new iteration method for finding a common element for the set of solutions of equilibrium
\end{abstract} problems and of operator equations with a finite family of $\lambda_{i}$-inverse-strongly monotone mappings in Hilbert spaces.

\section{Introduction}

Let $H$ be a real Hilbert space with the inner product $\langle\cdot, \cdot\rangle$ and the norm $\|\cdot\|$, respectively. Let $C$ be a nonempty closed convex subset of $H$, and let $G$ be a bifunction from $C \times C$ into $(-\infty,+\infty)$. The equilibrium problem for $G$ is to find $u^{*} \in C$ such that

$$
G\left(u^{*}, v\right) \geq 0, \quad \forall v \in C .
$$

The set of solutions of (1) is denoted by $\operatorname{EP}(G)$.

Equilibrium problem (1) includes the numerous problems in physics, optimization, economics, transportation, and engineering, as special cases.

Assume that the bifunction $G$ satisfies the following standard properties.

Assumption A. Let $G: C \times C \rightarrow(-\infty,+\infty)$ be a bifunction satisfying the conditions (A1)-(A4):

(A1) $G(u, u)=0, \forall u \in C$;

(A2) $G(u, v)+G(v, u) \leq 0, \forall(u, v) \in C \times C$;

(A3) for each $u \in C, G(u, \cdot): C \rightarrow(-\infty,+\infty)$ is lower semicontinuous and convex;

(A4) $\varlimsup_{t \rightarrow+0} G((1-t) u+t z, v) \leq G(u, v), \forall(u, z, v) \in C \times$ $C \times C$.
Let $\left\{T_{i}\right\}, i=1, \ldots, N$, be a finite family of $k_{i}$-strictly pseudocontractive mappings from $C$ into $C$ with the set of fixed points $F\left(T_{i}\right)$; that is,

$$
F\left(T_{i}\right)=\left\{x \in C: T_{i} x=x\right\} .
$$

Assume that

$$
\mathcal{S}:=\bigcap_{i=1}^{N} F\left(T_{i}\right) \cap \mathrm{EP}(G) \neq \emptyset .
$$

The problem of finding an element

$$
u^{*} \in \mathcal{S}
$$

is studied intensively in [1-27].

Recall that a mapping $T$ in $H$ is said to be a $k$-strictly pseudocontractive mapping in the terminology of Browder and Petryshyn [28] if there exists a constant $0 \leq k<1$ such that

$$
\|T x-T y\|^{2} \leq\|x-y\|^{2}+k\|(I-T) x-(I-T) y\|^{2},
$$

for all $x, y \in D(T)$, the domain of $T$, where $I$ is the identity operator in $H$. Clearly, if $k=0$, then $T$ is nonexpansive; that is,

$$
\|T(x)-T(y)\| \leq\|x-y\| .
$$


We know that the class of $k$-strictly pseudocontractive mappings strictly includes the class of nonexpansive mappings.

In the case that $T_{i} \equiv I,(4)$ is reduced to the equilibrium problem (1) and shown in $[5,23]$ to cover monotone inclusion problems, saddle point problems, variational inequality problems, minimization problems, Nash equilibria in noncooperative games, vector equilibrium problems, and certain fixed point problems (see also [29]). For finding approximative solutions of (1) there exist several methods: the regularization approach in $[7,9,15,24,30,31]$, the gap-function approach in $[8,15,16,18,19]$, and the iterative procedure approach in $[1-$ $4,6,8,11-14,19-22,32,33]$.

In the case that $G \equiv 0$ and $N=1,(4)$ is a problem of finding a fixed point for a $k$-strictly pseudocontractive mapping in $C$ and is given by Marino and $\mathrm{Xu}$ [17].

Theorem 1 (see [17]). Let $C$ be a nonempty closed convex subset of a real Hilbert space $H$. Let $T: C \rightarrow C$ be a $k$-strictly pseudocontractive mapping for some $0 \leq k<1$, and assume that

$$
F(T) \neq \emptyset \text {. }
$$

Let $\left\{x_{n}\right\}$ be the sequence generated by the following algorithm:

$$
\begin{gathered}
x_{0} \in C, \\
y_{n}=\alpha_{n} x_{n}+\left(1-\alpha_{n}\right) T x_{n}, \\
C_{n}=\left\{z \in C:\left\|y_{n}-z\right\|^{2} \leq\left\|x_{n}-z\right\|^{2}\right. \\
\left.+\left(1-\alpha_{n}\right)\left(k-\alpha_{n}\right)\left\|x_{n}-T x_{n}\right\|^{2}\right\}, \\
Q_{n}=\left\{z \in C:\left\langle x_{n}-z, x_{0}-x_{n}\right\rangle \geq 0\right\}, \\
x_{n+1}=P_{C_{n} \cap Q_{n}} x_{0} .
\end{gathered}
$$

Assume that the control sequence $\left\{\alpha_{n}\right\}$ is chosen so that $\alpha_{n}<1$ for all $n$. Then $\left\{x_{n}\right\}$ converges strongly to $P_{F(T)} x_{0}$, the projection of $x_{0}$ onto $F(T)$.

For the case that $G \equiv 0$ and $N>1$, (4) is a problem of finding a common fixed point for a finite family of $k_{i}$-strictly pseudocontractive mappings $T_{i}$ in $C$ and is studied in [27].

Let $x_{0} \in C$ and $\left\{\alpha_{n}\right\},\left\{\beta_{n}\right\}$, and $\left\{\gamma_{n}\right\}$ three sequences in $[0,1]$ satisfying $\alpha_{n}+\beta_{n}+\gamma_{n}=1$ for all $n \geq 1$, and let $\left\{u_{n}\right\}$ be a sequence in $C$. Then the sequence $\left\{x_{n}\right\}$ generated by

$$
\begin{aligned}
& x_{1}=\alpha_{1} x_{0}+\beta_{1} T_{1} x_{1}+\gamma_{1} u_{1}, \\
& x_{2}=\alpha_{2} x_{1}+\beta_{2} T_{2} x_{2}+\gamma_{2} u_{2}, \\
& \vdots \\
& x_{N}=\alpha_{N} x_{N-1}+\beta_{N} T_{N} x_{N}+\gamma_{N} u_{N}, \\
& x_{N+1}=\alpha_{N+1} x_{N}+\beta_{N+1} T_{1} x_{N+1}+\gamma_{N+1} u_{N+1},
\end{aligned}
$$

is called the implicit iteration process with mean errors for a finite family of strictly pseudocontractive mappings $\left\{T_{i}\right\}_{i=1}^{N}$.

The scheme (9) can be expressed in the compact form as

$$
x_{n}=\alpha_{n} x_{n-1}+\beta_{n} T_{n} x_{n}+\gamma_{n} u_{n},
$$

where $T_{n}=T_{n \bmod N}$.

Theorem 2 (see [27]). Let $C$ be a nonempty closed convex subset of a real Hilbert space H. Let $\left\{T_{i}\right\}_{i=1}^{N}$ be a finite family of strictly pseudocontractive mappings of $C$ into itself such that

$$
\bigcap_{i=1}^{N} F\left(T_{i}\right) \neq \emptyset .
$$

Let $x_{0} \in C$ and let $\left\{u_{n}\right\}$ be a bounded sequence in $C$; let $\left\{\alpha_{n}\right\},\left\{\beta_{n}\right\}$, and $\left\{\gamma_{n}\right\}$ be three sequences in $[0,1]$ satisfying the following conditions:

(i) $\alpha_{n}+\beta_{n}+\gamma_{n}=1, \forall n \geq 1$;

(ii) there exist constants $\sigma_{1}, \sigma_{2}$ such that $0<\sigma_{1} \leq \beta_{n} \leq$ $\sigma_{2}<1, \forall n \geq 1$;

(iii) $\sum_{n=1}^{\infty} \gamma_{n}<\infty$.

Then the implicit iterative sequence $\left\{x_{n}\right\}$ defined by (9) converges weakly to a common fixed point of the mappings $\left\{T_{i}\right\}_{i=1}^{N}$. Moreover, if there exists $i_{0} \in\{1,2, \ldots, N\}$ such that $T_{i_{0}}$ is demicompact, then $\left\{x_{n}\right\}$ converges strongly.

If $G$ is an arbitrary bifunction satisfying Assumption A and $N=1$, then (4) is a problem of finding a common element of the fixed point set for a $k$-strictly pseudocontractive mapping in $C$ and of the solution set of equilibrium problem for $G$ (see [26]).

Theorem 3 (see [26]). Let $C$ be a nonempty closed convex subset of a real Hilbert space $H$. Let $G$ be a bifunction from $C \times C$ to $(-\infty,+\infty)$ satisfying Assumption $A$, and let $T$ be a nonexpansive mapping of $C$ into $H$ such that

$$
F(T) \cap E P(G) \neq \emptyset .
$$

Let $f$ be a contraction of $H$ into itself and let $\left\{x_{n}\right\}$ and $\left\{u_{n}\right\}$ be sequences generated by $x_{1} \in H$ and

$$
\begin{gathered}
G\left(u_{n}, y\right)+\frac{1}{r_{n}}\left\langle y-u_{n}, u_{n}-x_{n}\right\rangle \geq 0, \quad \forall y \in C, \\
x_{n+1}=\alpha_{n} f\left(x_{n}\right)+\left(1-\alpha_{n}\right) T u_{n}
\end{gathered}
$$

for all $n \in \mathbf{N}$, where $\left\{\alpha_{n}\right\} \subset[0,1]$ and $\left\{r_{n}\right\} \subset(0, \infty)$ satisfy

$$
\begin{gathered}
\lim _{n \rightarrow \infty} \alpha_{n}=0, \quad \sum_{n=1}^{\infty} \alpha_{n}=\infty, \quad \sum_{n=1}^{\infty}\left|\alpha_{n+1}-\alpha_{n}\right|<\infty, \\
\liminf _{n \rightarrow \infty} r_{n}>0, \quad \sum_{n=1}^{\infty}\left|r_{n+1}-r_{n}\right|<\infty .
\end{gathered}
$$

Then, $\left\{x_{n}\right\}$ and $\left\{u_{n}\right\}$ converge strongly to $z \in F(T) \cap E P(G)$, where

$$
z=P_{F(T) \cap E P(G)} f(z) .
$$


Set $A_{i}=I-T_{i}$. Obviously, $A_{i}$ are $\lambda_{i}$-inverse-strongly monotone; that is,

$$
\begin{array}{r}
\left\langle A_{i}(x)-A_{i}(y), x-y\right\rangle \geq \lambda_{i}\left\|A_{i}(x)-A_{i}(y)\right\|^{2}, \\
\forall x, y \in D\left(A_{i}\right), \quad \lambda_{i}=\frac{1-k_{i}}{2} .
\end{array}
$$

From now on, let $\left\{A_{i}\right\}_{i=1}^{N}$ be a finite family of $\lambda_{i}$-inversestrongly monotone mappings in $H$ with $C \subset \bigcap_{i=1}^{N} D\left(A_{i}\right)$ and $\lambda_{i}>0, i=1, \ldots, N$. On the other hand, if there exists $i_{0} \in$ $\{1,2, \ldots, N\}$ such that $\lambda_{i_{0}}>1$, then $A_{i_{0}}$ is a contraction; that is, $\left\|A_{i_{0}}(x)-A_{i_{0}}(y)\right\| \leq\left(1 / \lambda_{i_{0}}\right)\|x-y\|$ with $1 / \lambda_{i_{0}}<1$. And hence, $A_{i_{0}}$ has only one solution and, consequently, the stated problem does not have sense. So, without loss of generality, assume that $0<\lambda_{i} \leq 1, i=1, \ldots, N$.

Set

$$
S=\bigcap_{i=1}^{N} S_{i},
$$

where $S_{i}=\left\{x \in C: A_{i}(x)=0\right\}$ is the solution set of $A_{i}$ in $C$.

Assume that $\operatorname{EP}(G) \cap S \neq \emptyset$.

Our problem is to find an element

$$
u^{*} \in \operatorname{EP}(G) \cap S \text {. }
$$

Since the mapping $A=I-T$ is (1/2)-inverse-strongly monotone for each nonexpansive mapping $T$, the problem of finding an element $u^{*} \in C$, which is not only a solution of a variational inequality involving an inverse-strongly monotone mapping but also a fixed point of a nonexpansive mapping, is a particular case of (18).

For instance, the case that $G(u, v) \equiv\langle A(u), v-u\rangle$, where $A$ is some inverse-strongly monotone mapping and $N=1$, is studied in [25].

Theorem 4 (see [25]). Let $C$ be a nonempty closed convex subset of a real Hilbert space $H$. Let $\lambda>0$. Let $A$ be a $\lambda$ inverse-strongly monotone mapping of $C$ into $H$, and let $T$ be a nonexpansive mapping of $C$ into itself such that

$$
F(T) \cap V I(C, A) \neq \emptyset,
$$

where $\operatorname{VI}(C, A)$ denotes the solution set of the following variational inequality: find $x^{*} \in C$ such that

$$
\left\langle A\left(x^{*}\right), x-x^{*}\right\rangle \geq 0, \quad \forall x \in C .
$$

Let $\left\{x_{n}\right\}$ be a sequence defined by

$$
\begin{gathered}
x_{0} \in C, \\
x_{n+1}=\alpha_{n} x_{n}+\left(1-\alpha_{n}\right) T P_{C}\left(x_{n}-\lambda_{n} A\left(x_{n}\right)\right),
\end{gathered}
$$

for every $n=0,1, \ldots$, where $\left\{\lambda_{n}\right\} \subset[a, b]$ for some $a, b \in$ $(0,2 \lambda)$ and $\left\{\alpha_{n}\right\} \subset(c, d)$ for some $c, d \in(0,1)$. Then, $\left\{x_{n}\right\}$ converges weakly to $z \in F(T) \cap V I(C, A)$, where

$$
z=\lim _{n \rightarrow \infty} P_{F(T) \cap V I(C, A)} x_{n}
$$

The following theorem is an improvement of Theorem 4 for the case of nonself-mapping.

Theorem 5 (see [34]). Let $C$ be a nonempty closed convex subset of a real Hilbert space $H$. Let $A$ be a $\lambda$-inverse-strongly monotone mapping of $C$ into $H$, and let $T$ be a nonexpansive nonself-mapping of $C$ into $H$ such that

$$
F(T) \cap V I(C, A) \neq \emptyset .
$$

Suppose that $x_{1}=x \in C$ and $\left\{x_{n}\right\}$ is given by

$$
x_{n+1}=P_{C}\left(\alpha_{n} x+\left(1-\alpha_{n}\right) T P_{C}\left(x_{n}-\lambda_{n} A\left(x_{n}\right)\right)\right)
$$

for every $n=1,2, \ldots$, where $\left\{\alpha_{n}\right\}$ is a sequence in $[0,1)$ and $\left\{\lambda_{n}\right\}$ is a sequence in $[0,2 \alpha]$. If $\left\{\alpha_{n}\right\}$ and $\left\{\lambda_{n}\right\}$ are chosen so that $\lambda_{n} \in[a, b]$ for some $a, b$ with $0<a<b<2 \alpha$,

$$
\begin{array}{cl}
\lim _{n \rightarrow \infty} \alpha_{n}=0, & \sum_{n=1}^{\infty} \alpha_{n}=\infty, \\
\sum_{n=1}^{\infty}\left|\alpha_{n+1}-\alpha_{n}\right|<\infty, & \sum_{n=1}^{\infty}\left|\lambda_{n+1}-\lambda_{n}\right|<\infty,
\end{array}
$$

then $\left\{x_{n}\right\}$ converges strongly to $P_{F(T) \cap V I(C, A)} x$.

We know that $\lambda$-inverse-strongly monotone mapping is $(1 / \lambda)$-Lipschitz continuous and monotone. Therefore, for the case that $G(u, v) \equiv\langle A(u), v-u\rangle$, where $A$ is not inversestrongly monotone, but Lipschitz continuous and monotone, Nadezhkina and Takahashi [35] prove the following theorem.

Theorem 6 (see [35]). Let $C$ be a nonempty closed convex subset of a real Hilbert space $H$. Let $A$ be a monotone and $k$-Lipschitz continuous mapping of $C$ into $H$, and let $T$ be a nonexpansive mapping of $C$ into itself such that

$$
F(T) \cap V I(C, A) \neq \emptyset .
$$

Let $\left\{x_{n}\right\},\left\{y_{n}\right\}$, and $\left\{z_{n}\right\}$ be sequences generated by

$$
\begin{gathered}
x_{0}=x \in C, \\
y_{n}=P_{C}\left(x_{n}-\lambda_{n} A\left(x_{n}\right)\right), \\
z_{n}=P_{C}\left(x_{n}-\lambda_{n} A\left(y_{n}\right)\right), \\
C_{n}=\left\{z \in C:\left\|z_{n}-z\right\| \leq\left\|x_{n}-z\right\|\right\}, \\
Q_{n}=\left\{z \in C:\left\langle x_{n}-z, x-x_{n}\right\rangle \geq 0\right\}, \\
x_{n+1}=P_{C_{n} \cap Q_{n}} x
\end{gathered}
$$

for every $n=0,1, \ldots$, where $\left\{\lambda_{n}\right\} \subset[a, b]$ for some $a, b \in$ $(0,1 / k)$ and $\alpha_{n} \subset[0, c]$ for some $c \in[0,1)$. Then the sequences $\left\{x_{n}\right\},\left\{y_{n}\right\}$, and $\left\{z_{n}\right\}$ converge strongly to $P_{F(T) \cap V I(C, A)} x$.

Some similar results are also considered in $[36,37]$.

Buong [38] introduced two new implicit iteration methods for solving problem (18).

We construct a regularization solution $u_{n}$ of the following single equilibrium problem: find $u_{n} \in C$ such that

$$
\mathscr{F}\left(u_{n}, v\right) \geq 0, \quad \forall v \in C,
$$


where

$$
\begin{gathered}
\mathscr{F}(u, v):=G(u, v)+\sum_{i=1}^{N} \alpha_{n}^{\mu_{i}} G_{i}(u, v)+\alpha_{n}\langle u, v-u\rangle, \\
\alpha_{n}>0, \\
G_{i}(u, v)=\left\langle A_{i}(u), v-u\right\rangle, \quad i=1, \ldots, N, \\
0<\mu_{i}<\mu_{i+1}<1, \quad i=2, \ldots, N-1,
\end{gathered}
$$

and $\left\{\alpha_{n}\right\}$ is the positive sequence of regularization parameters that converges to 0 , as $n \rightarrow+\infty$.

The first one is the following theorem.

Theorem 7 (see [38]). For each $\alpha_{n}>0$, problem (28) has a unique solution $u_{n}$ such that

(i) $\lim _{n \rightarrow+\infty} u_{n}=u^{*}, u^{*} \in E P(G) \cap S,\left\|u^{*}\right\| \leq\|y\|, \forall y \in$ $E P(G) \cap S$

(ii)

$$
\left\|u_{n}-u_{m}\right\| \leq\left(\left\|u^{*}\right\|+d N\right) \frac{\left|\alpha_{n}-\alpha_{m}\right|}{\alpha_{n}},
$$

where $d$ is a positive constant.

Next, we introduce the second result. Let $\left\{\widetilde{c}_{n}\right\}$ and $\left\{\gamma_{n}\right\}$ be some sequences of positive numbers, and let $z_{0}$ and $z_{1}$ be two arbitrary elements in $C$. Then, the sequence $\left\{z_{n}\right\}$ of iterations is defined by the following equilibrium problem: find $z_{n+1} \epsilon$ $C$ such that

$$
\begin{aligned}
& \widetilde{c}_{n}\left(G\left(z_{n+1}, v\right)+\sum_{i=1}^{N} \alpha_{n}^{\mu_{i}} G_{i}\left(z_{n+1}, v\right)+\alpha_{n}\left\langle z_{n+1}, v-z_{n+1}\right\rangle\right) \\
& \quad+\left\langle z_{n+1}-z_{n}, v-z_{n+1}\right\rangle-\gamma_{n}\left\langle z_{n}-z_{n-1}, v-z_{n+1}\right\rangle \geq 0,
\end{aligned}
$$$$
\forall v \in C \text {. }
$$

Theorem 8 (see [38]). Assume that the parameters $\widetilde{c}_{n}, \gamma_{n}$, and $\alpha_{n}$ are chosen such that

(i) $0<c_{0}<\widetilde{c}_{n}, 0 \leq \gamma_{n}<\gamma_{0}$,

(ii) $\sum_{n=1}^{\infty} b_{n}=+\infty, b_{n}=\widetilde{c}_{n} \alpha_{n} /\left(1+\widetilde{c}_{n} \alpha_{n}\right)$,

(iii) $\sum_{n=1}^{\infty} \gamma_{n} b_{n}^{-1}\left\|z_{n}-z_{n-1}\right\|<+\infty$,

(iv) $\lim _{n \rightarrow \infty} \alpha_{n}=0, \lim _{n \rightarrow \infty}\left(\left|\alpha_{n}-\alpha_{n+1}\right| / \alpha_{n} b_{n}\right)=0$.

Then, the sequence $\left\{z_{n}\right\}$ defined by (31) converges strongly to the element $u^{*}$, as $n \rightarrow+\infty$.
In this paper, we consider the new another iteration method: for an arbitrary element $x_{0}$ in $H$, the sequence $\left\{x_{n}\right\}$ of iterations is defined by finding $u_{n} \in C$ such that

$$
\begin{gathered}
G\left(u_{n}, y\right)+\left\langle u_{n}-x_{n}, y-u_{n}\right\rangle \geq 0, \quad \forall y \in C, \\
x_{n+1}=P_{C}\left(x_{n}-\beta_{n}\left[x_{n}-u_{n}+\sum_{i=1}^{N} \alpha_{n}^{\mu_{i}} A_{i}\left(x_{n}\right)+\alpha_{n} x_{n}\right]\right) \\
=P_{C}\left(x_{n}-\beta_{n}\left[\sum_{i=1}^{N} \alpha_{n}^{\mu_{i}} A_{i}\left(x_{n}\right)+\left(1+\alpha_{n}\right) x_{n}-u_{n}\right]\right),
\end{gathered}
$$

where $P_{C}$ is the metric projection of $H$ onto $C$ and $\left\{\alpha_{n}\right\}$ and $\left\{\beta_{n}\right\}$ are sequences of positive numbers.

The strong convergence of the sequence $\left\{x_{n}\right\}$ defined by (32) is proved under some suitable conditions on $\left\{\alpha_{n}\right\}$ and $\left\{\beta_{n}\right\}$ in the next section.

\section{Main Results}

We formulate the following lemmas for the proof of our main theorems.

Lemma 9 (see [9]). Let $C$ be a nonempty closed convex subset of a real Hilbert space $H$ and let $G$ be a bifunction of $C \times C$ into $(-\infty,+\infty)$ satisfying Assumption A. Let $r>0$ and $x \in H$. Then, there exists $z \in C$ such that

$$
G(z, y)+\frac{1}{r}\langle z-x, y-z\rangle \geq 0, \quad \forall y \in C .
$$

Lemma 10 (see [9]). Let C be a nonempty closed convex subset of a real Hilbert space $H$. Assume that $G: C \times C \rightarrow$ $(-\infty,+\infty)$ satisfies Assumption A. For $r>0$ and $x \in H$, define a mapping $T_{r}: H \rightarrow C$ as follows:

$$
T_{r}(x)=\left\{z \in C: G(z, y)+\frac{1}{r}\langle z-x, y-z\rangle \geq 0\right\}, \quad \forall y \in C .
$$

Then, the following statements hold:

(i) $T_{r}$ is single valued;

(ii) $T_{r}$ is firmly nonexpansive; that is, for any $x, y \in H$,

$$
\left\|T_{r}(x)-T_{r}(y)\right\|^{2} \leq\left\langle T_{r}(x)-T_{r}(y), x-y\right\rangle ;
$$

(iii) $F\left(T_{r}\right)=E P(G)$;

(iv) $E P(G)$ is closed and convex.

Lemma 11 (see [36]). Let $\left\{a_{n}\right\},\left\{b_{n}\right\}$, and $\left\{c_{n}\right\}$ be the sequences of positive numbers satisfying the following conditions:

(i) $a_{n+1} \leq\left(1-b_{n}\right) a_{n}+c_{n}$,

(ii) $\sum_{n=0}^{\infty} b_{n}=+\infty, b_{n}<1, \lim _{n \rightarrow+\infty}\left(c_{n} / b_{n}\right)=0$.

Then, $\lim _{n \rightarrow+\infty} a_{n}=0$. 
Lemma 12 (see [38]). Let $A$ be any inverse-strongly monotone mapping from $C$ into $H$ with the solution set $S_{A}:=\{x \in C$ : $A(x)=0\}$, and let $C_{0}$ be a closed convex subset of $C$ such that

$$
S_{A} \cap C_{0} \neq \emptyset .
$$

Then, the solution set of the following variational inequality

$$
\langle A(\tilde{y}), x-\tilde{y}\rangle \geq 0, \quad \forall x \in C_{0}, \tilde{y} \in C_{0},
$$

is coincided with $S_{A} \cap C_{0}$.

From Lemma 9, we can consider the firmly nonexpansive mapping $T_{0}$ defined by

$$
\begin{array}{r}
T_{0}(x)=\{z \in C: G(z, y)+\langle z-x, y-z\rangle \geq 0, \quad \forall y \in C\}, \\
\forall x \in H .
\end{array}
$$

From Lemma 10, we know that $T_{0}$ is nonexpansive. Consequently, $A_{0}:=I-T_{0}$ is (1/2)-inverse-strongly monotone. Let

$$
S_{0}:=\left\{x \in C: A_{0}(x)=0\right\} .
$$

Then, $S_{0}=\operatorname{EP}(G)$ and problem (18) are equivalent to finding

$$
u^{*} \in S_{0} \cap S \text {. }
$$

Now, we construct a regularization solution $y_{n}$ for (40) by solving the following variational inequality problem: find $y_{n} \in C$ such that

$$
\begin{gathered}
\left\langle\sum_{i=0}^{N} \alpha_{n}^{\mu_{i}} A_{i}\left(y_{n}\right)+\alpha_{n} y_{n}, v-y_{n}\right\rangle \geq 0, \quad \forall v \in C, \\
\mu_{0}=0<\mu_{1}<\cdots<\mu_{N}<1,
\end{gathered}
$$

where the positive regularization parameter $\alpha_{n} \rightarrow 0$, as $n \rightarrow$ $+\infty$.

Now we are in a position to introduce and prove the main results.

Theorem 13. Let $C$ be a nonempty closed convex subset of a real Hilbert space $H$. Let $G$ be a bifunction from $C \times C$ to $(-\infty,+\infty)$ satisfying Assumption $A$ and let $\left\{A_{i}\right\}_{i=1}^{N}$ be a finite family of $\lambda_{i}$-inverse-strongly monotone mappings in $H$ with $C \subset \bigcap_{i=1}^{N} D\left(A_{i}\right)$ and $\lambda_{i}>0, i=1, \ldots, N$, such that

$$
E P(G) \cap S \neq \emptyset,
$$

where $\operatorname{EP}(G)$ denotes the set of solutions for (1) and

$$
S=\bigcap_{i=1}^{N} S_{i}, \quad S_{i}=\left\{x \in C: A_{i}(x)=0\right\} .
$$

Then, for each $\alpha_{n}>0$, problem (41) has a unique solution $y_{n}$ such that

(i) $\lim _{n \rightarrow+\infty} y_{n}=u^{*}, u^{*} \in E P(G) \cap S$,

(ii) $\left\|u^{*}\right\| \leq\|y\|, \forall y \in E P(G) \cap S$, (iii)

$$
\left\|y_{n}-y_{m}\right\| \leq \frac{\left|\alpha_{n}-\alpha_{m}\right|}{\alpha_{n}}\left(\left\|u^{*}\right\|+d N\right),
$$

where $d$ is some positive constant.

Proof. From Lemma 12, we know that $S_{0}$ is the set of solutions for the following variational inequality problem: find $u^{*} \in C$ such that

$$
\left\langle A_{0}\left(u^{*}\right), v-u^{*}\right\rangle \geq 0, \quad \forall v \in C .
$$

If we define the new bifunction $G_{0}(u, v)$ by

$$
G_{0}(u, v)=\left\langle A_{0}\left(u^{*}\right), v-u^{*}\right\rangle,
$$

then problem (41) is the same as $(28)$ with a new $G(u, v)$, and the proof for the theorem is a complete repetition of the proof for Theorem 2.1 in [38].

Set

$$
L=\max \left\{2, \frac{1}{\lambda_{i}}, i=1, \ldots, N\right\}
$$

Theorem 14. Let $C$ be a nonempty closed convex subset of a real Hilbert space $H$. Let $G$ be a bifunction from $C \times C$ to $(-\infty,+\infty)$ satisfying Assumption $A$ and let $\left\{A_{i}\right\}_{i=1}^{N}$ be a finite family of $\lambda_{i}$-inverse-strongly monotone mappings in $H$ with $C \subset \bigcap_{i=1}^{N} D\left(A_{i}\right)$ and $\lambda_{i}>0, i=1, \ldots, N$, such that

$$
E P(G) \cap S \neq \emptyset,
$$

where $\operatorname{EP}(G)$ denotes the set of solutions for (1) and

$$
S=\bigcap_{i=1}^{N} S_{i}, \quad S_{i}=\left\{x \in C: A_{i}(x)=0\right\} .
$$

Suppose that $\alpha_{n}, \beta_{n}$ satisfy the following conditions:

$$
\begin{gathered}
\alpha_{n}, \beta_{n}>0\left(\alpha_{n} \leq 1\right), \quad \lim _{n \rightarrow \infty} \alpha_{n}=0, \\
\lim _{n \rightarrow \infty} \frac{\left|\alpha_{n}-\alpha_{n+1}\right|}{\alpha_{n}^{2} \beta_{n}}=0, \quad \sum_{n=0}^{\infty} \alpha_{n} \beta_{n}=\infty, \\
\varlimsup_{n \rightarrow \infty} \beta_{n} \frac{\left(L(N+1)+\alpha_{n}\right)^{2}}{\alpha_{n}}<1 .
\end{gathered}
$$

Then, the sequence $\left\{x_{n}\right\}$ defined by (32) converges strongly to $u^{*} \in E P(G) \cap S$; that is,

$$
\lim _{n \rightarrow \infty} x_{n}=u^{*} \in \operatorname{EP}(G) \cap S .
$$

Proof. Let $y_{n}$ be the solution of (41). Then,

$$
y_{n}=P_{C}\left(y_{n}-\beta_{n}\left[\sum_{i=0}^{N} \alpha_{n}^{\mu_{i}} A_{i}\left(y_{n}\right)+\alpha_{n} y_{n}\right]\right) .
$$


Set $\Delta_{n}=\left\|x_{n}-y_{n}\right\|$. Obviously,

$$
\Delta_{n+1}=\left\|x_{n+1}-y_{n+1}\right\| \leq\left\|x_{n+1}-y_{n}\right\|+\left\|y_{n+1}-y_{n}\right\|
$$

From the nonexpansivity of $P_{C}$, the monotone and Lipschitz continuous properties of $A_{i}, i=0, \ldots, N,(41),(52)$, and $y_{n}=$ $T_{0}\left(x_{n}\right)$, we have

$$
\begin{aligned}
& \left\|x_{n+1}-y_{n}\right\| \\
& \leq \| x_{n}-y_{n}-\beta_{n}\left[\sum_{i=0}^{N} \alpha_{n}^{\mu_{i}}\left(A_{i}\left(x_{n}\right)-A_{i}\left(y_{n}\right)\right)\right. \\
& \left.+\alpha_{n}\left(x_{n}-y_{n}\right)\right] \| \\
& \left\|x_{n}-y_{n}-\beta_{n}\left[\sum_{i=0}^{N} \alpha_{n}^{\mu_{i}}\left(A_{i}\left(x_{n}\right)-A_{i}\left(y_{n}\right)\right)+\alpha_{n}\left(x_{n}-y_{n}\right)\right]\right\|^{2} \\
& =\left\|x_{n}-y_{n}\right\|^{2} \\
& +\beta_{n}^{2}\left\|\left[\sum_{i=0}^{N} \alpha_{n}^{\mu_{i}}\left(A_{i}\left(x_{n}\right)-A_{i}\left(y_{n}\right)\right)+\alpha_{n}\left(x_{n}-y_{n}\right)\right]\right\|^{2} \\
& -2 \beta_{n}\left\langle\sum_{i=0}^{N} \alpha_{n}^{\mu_{i}}\left(A_{i}\left(x_{n}\right)-A_{i}\left(y_{n}\right)\right)\right. \\
& \left.+\alpha_{n}\left(x_{n}-y_{n}\right), x_{n}-y_{n}\right\rangle \\
& \leq\left\|x_{n}-y_{n}\right\|^{2}\left[1-2 \beta_{n} \alpha_{n}+\beta_{n}^{2}\left(2+\sum_{i=1}^{N} \alpha_{n}^{\mu_{i}} \frac{1}{\lambda_{i}}+\alpha_{n}\right)^{2}\right] \text {. }
\end{aligned}
$$

Thus,

$$
\left\|x_{n+1}-y_{n}\right\| \leq \Delta_{n}\left(1-2 \beta_{n} \alpha_{n}+\beta_{n}^{2}\left(L(N+1)+\alpha_{n}\right)^{2}\right)^{1 / 2} \text {. }
$$

Therefore,

$$
\begin{aligned}
\Delta_{n+1} \leq & \Delta_{n}\left(1-2 \beta_{n} \alpha_{n}+\beta_{n}^{2}\left(L(N+1)+\alpha_{n}\right)^{2}\right)^{1 / 2} \\
& +\frac{\left|\alpha_{n}-\alpha_{n+1}\right|}{\alpha_{n}}\left(\left\|u^{*}\right\|+d N\right) \\
\leq & \Delta_{n}\left(1-\alpha_{n} \beta_{n}\right)^{1 / 2}+\frac{\left|\alpha_{n}-\alpha_{n+1}\right|}{\alpha_{n}}\left(\left\|u^{*}\right\|+d N\right) .
\end{aligned}
$$

We note that, for $\varepsilon>0, a>0, b>0$, the inequality

$$
(a+b)^{2} \leq(1+\varepsilon)\left(a^{2}+\frac{b^{2}}{\varepsilon}\right)
$$

holds. Thus, applying inequality (57) for $\varepsilon=\alpha_{n} \beta_{n} / 2$, we obtain

$$
\begin{aligned}
0 \leq & \Delta_{n+1}^{2} \\
\leq & \Delta_{n}^{2}\left(1-\alpha_{n} \beta_{n}\right)\left(1+\frac{1}{2} \alpha_{n} \beta_{n}\right) \\
& +\left(\frac{\alpha_{n}-\alpha_{n+1}}{\alpha_{n}}\left(\left\|u^{*}\right\|+d N\right)\right)^{2} \frac{2}{\alpha_{n} \beta_{n}}\left(1+\frac{1}{2} \alpha_{n} \beta_{n}\right) \\
= & \Delta_{n}^{2}\left(1-\frac{1}{2} \alpha_{n} \beta_{n}-\frac{1}{2}\left(\alpha_{n} \beta_{n}\right)^{2}\right) \\
& +\left(\frac{\alpha_{n}-\alpha_{n+1}}{\alpha_{n}^{2} \beta_{n}}\left(\left\|u^{*}\right\|+d N\right)\right)^{2} 2 \alpha_{n} \beta_{n}\left(1+\frac{1}{2} \alpha_{n} \beta_{n}\right) .
\end{aligned}
$$

Set

$$
\begin{gathered}
b_{n}=\alpha_{n} \beta_{n}\left(\frac{1}{2}+\frac{1}{2} \alpha_{n} \beta_{n}\right) \\
c_{n}=\left(\frac{\alpha_{n}-\alpha_{n+1}}{\alpha_{n}^{2} \beta_{n}}\left(\left\|u^{*}\right\|+d N\right)\right)^{2} 2 \alpha_{n} \beta_{n}\left(1+\frac{1}{2} \alpha_{n} \beta_{n}\right) .
\end{gathered}
$$

Then, it is not difficult to check that $b_{n}$ and $c_{n}$ satisfy the conditions in Lemma 11 for sufficiently large $n$. Hence, $\lim _{n \rightarrow+\infty} \Delta_{n}^{2}=0$. Since $\lim _{n \rightarrow \infty} y_{n}=u^{*}$, we have

$$
\lim _{n \rightarrow \infty} x_{n}=u^{*} \in \operatorname{EP}(G) \cap S \text {. }
$$

This completes the proof.

Remark 15. The sequences $\alpha_{n}=(1+n)^{-p}, 0<p<1 / 2$, and $\beta_{n}=\gamma_{0} \alpha_{n}$ with

$$
0<\gamma_{0}<\frac{1}{\left(L(N+1)+\alpha_{0}\right)^{2}}
$$

satisfy all the necessary conditions in Theorem 14 .

\section{Conflict of Interests}

The authors declare that there is no conflict of interests regarding the publication of this paper.

\section{Authors' Contribution}

The main idea of this paper was proposed by Jong Kyu Kim. Jong Kyu Kim and Nguyen Buong prepared the paper initially and performed all the steps of proof in this research. All authors read and approved the final paper.

\section{Acknowledgment}

This paper was supported by Basic Science Research Program through the National Research Foundation of Korea (NRF) funded by the Ministry of Education, Science and Technology (2012R1A1A2042138). 


\section{References}

[1] A. S. Antipin, "Equilibrium programming: gradient methods," Automation and Remote Control, vol. 58, no. 8, pp. 1337-1347, 1997.

[2] A. S. Antipin, "Equilibrium programming: proximal methods," Zhurnal Vychislite'noi Matematiki i Matematicheskoi Fiziki, vol. 37, no. 11, pp. 1327-1339, 1997, Computational Mathematics and Mathematical Physics, vol. 37, no. 11, pp. 1285-1296, 1997.

[3] A. S. Antipin, "Solution methods for variational inequalities with coupled constraints," Computational Mathematics and Mathematical Physics, vol. 40, no. 9, pp. 1239-1254, 2000, Translated from Zhurnal Vychislite'noi Matematiki i Matematicheskoi Fiziki, vol. 40, no. 9, 1291-1307, 2000.

[4] A. S. Antipin, "Solving variational inequalities with coupling constraints with the use of differential equations," Differential Equations, vol. 36, no. 11, pp. 1587-1596, 2000, Translated from Differentsial'nye Uravnenye, vol. 36, no. 11, 1443-1451, 2000.

[5] E. Blum and W. Oettli, "From optimization and variational inequalities to equilibrium problems," The Mathematics Student, vol. 63, no. 1-4, pp. 123-145, 1994.

[6] M. Bounkhel and B. R. Al-Senan, "An iterative method for nonconvex equilibrium problems," Journal of Inequalities in Pure and Applied Mathematics, vol. 7, no. 2, article 75, 2006.

[7] O. Chadli, S. Schaible, and J. C. Yao, "Regularized equilibrium problems with application to noncoercive hemivariational inequalities," Journal of Optimization Theory and Applications, vol. 121, no. 3, pp. 571-596, 2004.

[8] O. Chadli, I. V. Konnov, and J. C. Yao, "Descent methods for equilibrium problems in a Banach space," Computers \& Mathematics with Applications, vol. 48, no. 3-4, pp. 609-616, 2004.

[9] P. L. Combettes and S. A. Hirstoaga, "Equilibrium programming in Hilbert spaces," Journal of Nonlinear and Convex Analysis, vol. 6, no. 1, pp. 117-136, 2005.

[10] P. N. Anh and J. K. Kim, "An interior proximal cutting hyperplane method for equilibrium problems," Journal of Inequalities and Applications, vol. 2012, article 99, 2012.

[11] J. K. Kim, Y. M. Nam, and J. Y. Sim, "Convergence theorems of implicit iterative sequences for a finite family of asymptotically quasi-nonxpansive type mappings," Nonlinear Analysis: Theory, Methods \& Applications, vol. 71, no. 12, pp. 2839-2848, 2009.

[12] J. K. Kim, S. Y. Cho, and X. Qin, "Some results on generalized equilibrium problems involving strictly pseudocontractive mappings," Acta Mathematica Scientia. Series B, vol. 31, no. 5, pp. 2041-2057, 2011.

[13] J. K. Kim, "Strong convergence theorems by hybrid projection methods for equilibrium problems and fixed point problems of the asymptotically quasi- $\varphi$-nonexpansive mappings," Fixed Point Theory and Applications, vol. 2011, article 10, 2011.

[14] J. K. Kim and W. H. Lim, "A new iterative algorithm of pseudomonotone mappings for equilibrium problems in Hilbert spaces," Journal of Inequalities and Applications, vol. 2013, article 128, 2013.

[15] I. V. Konnov and O. V. Pinyagina, "D-gap functions and descent methods for a class of monotone equilibrium problems," Lobachevskii Journal of Mathematics, vol. 13, pp. 57-65, 2003.

[16] I. V. Konnov and O. V. Pinyagina, "D-gap functions for a class of equilibrium problems in Banach spaces," Computational Methods in Applied Mathematics, vol. 3, no. 2, pp. 274-286, 2003.

[17] G. Marino and H.-K. Xu, "Weak and strong convergence theorems for strict pseudo-contractions in Hilbert spaces,"
Journal of Mathematical Analysis and Applications, vol. 329, no. 1, pp. 336-346, 2007.

[18] G. Mastroeni, “Gap functions for equilibrium problems," Journal of Global Optimization, vol. 27, no. 4, pp. 411-426, 2003.

[19] G. Mastroeni, "On auxiliary principle for equilibrium problems," Tech. Rep. 3.244.1258, Department of Mathematics of Pisa University, Pisa, Italy, 2000.

[20] A. Moudafi, "Second-order differential proximal methods for equilibrium problems," Journal of Inequalities in Pure and Applied Mathematics, vol. 4, no. 1, article 18, 2003.

[21] A. Moudafi and M. Théra, "Proximal and dynamical approaches to equilibrium problems," in Ill-Posed Variational Problems and Regularization Techniques, vol. 477 of Lecture Notes in Economics and Mathematical Systems, pp. 187-201, Springer, Berlin, Germay, 1999.

[22] M. A. Noor and K. I. Noor, "On equilibrium problems," Applied Mathematics E-Notes, vol. 4, pp. 125-132, 2004.

[23] W. Oettli, "A remark on vector-valued equilibria and generalized monotonicity," Acta Mathematica Vietnamica, vol. 22, no. 1, pp. 213-221, 1997.

[24] A. S. Stukalov, "A regularized extragradient method for solving equilibrium programming problems in a Hilbert space," Zhurnal Vychislitel'noi Matematiki i Matematicheskoi Fiziki, vol. 45, no. 9, pp. 1538-1554, 2005.

[25] W. Takahashi and M. Toyoda, "Weak convergence theorems for nonexpansive mappings and monotone mappings," Journal of Optimization Theory and Applications, vol. 118, no. 2, pp. 417428, 2003.

[26] S. Takahashi and W. Takahashi, "Viscosity approximation methods for equilibrium problems and fixed point problems in Hilbert spaces," Journal of Mathematical Analysis and Applications, vol. 331, no. 1, pp. 506-515, 2007.

[27] G. Wang, J. Peng, and H.-W. J. Lee, "Implicit iteration process with mean errors for common fixed points of a finite family of strictly pseudocontrative maps," International Journal of Mathematical Analysis, vol. 1, no. 1-4, pp. 89-99, 2007.

[28] F. E. Browder and W. V. Petryshyn, "Construction of fixed points of nonlinear mappings in Hilbert space," Journal of Mathematical Analysis and Applications, vol. 20, pp. 197-228, 1967.

[29] A. Göpfert, H. Riahi, C. Tammer, and C. Zălinescu, Variational Methods in Partially Ordered Spaces, Springer, New York, NY, USA, 2003.

[30] J. K. Kim and T. M. Tuyen, "Regularization proximal point algorithm for finding a common fixed point of a finite family of nonexpansive mappings in Banach spaces," Fixed Point Theory and Applications, vol. 2011, article 52, 2011.

[31] J. K. Kim and N. Buong, "Regularization inertial proximal point algorithm for monotone hemicontinuous mapping and inverse strongly monotone mappings in Hilbert spaces," Journal of Inequalities and Applications, vol. 2010, Article ID 451916, 10 pages, 2010.

[32] J. K. Kim and N. Buong, "An iteration method for common solution of a system of equilibrium problems in Hilbert spaces," Fixed Point Theory and Applications, vol. 2011, Article ID 780764, 15 pages, 2011.

[33] J. K. Kim, P. N. Anh, and Y. M. Nam, "Strong convergence of an extended extragradient method for equilibrium problems and fixed point problems," Journal of the Korean Mathematical Society, vol. 49, no. 1, pp. 187-200, 2012. 
[34] H. Iiduka and W. Takahashi, "Strong convergence theorems for nonexpansive mappings and inverse-strongly monotone mappings," Nonlinear Analysis: Theory, Methods \& Applications, vol. 61, no. 3, pp. 341-350, 2005.

[35] N. Nadezhkina and W. Takahashi, "Strong convergence theorem by a hybrid method for nonexpansive mappings and Lipschitz-continuous monotone mappings," SIAM Journal on Optimization, vol. 16, no. 4, pp. 1230-1241, 2006.

[36] M. A. Noor, Y. Yao, R. Chen, and Y.-C. Liou, "An iterative method for fixed point problems and variational inequality problems," Mathematical Communications, vol. 12, no. 1, pp.121132, 2007.

[37] L.-C. Zeng and J.-C. Yao, "Strong convergence theorem by an extragradient method for fixed point problems and variational inequality problems," Taiwanese Journal of Mathematics, vol. 10, no. 5, pp. 1293-1303, 2006.

[38] N. Buong, "Approximation methods for equilibrium problems and common solution for a finite family of inverse stronglymonotone problems in Hilbert spaces," Applied Mathematical Sciences, vol. 2, no. 13-16, pp. 735-746, 2008. 


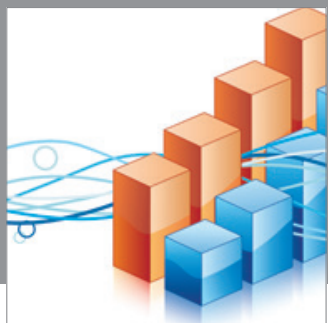

Advances in

Operations Research

mansans

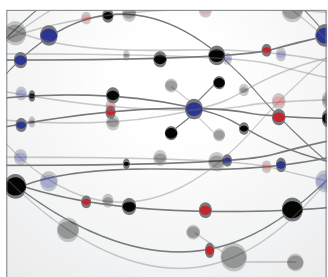

The Scientific World Journal
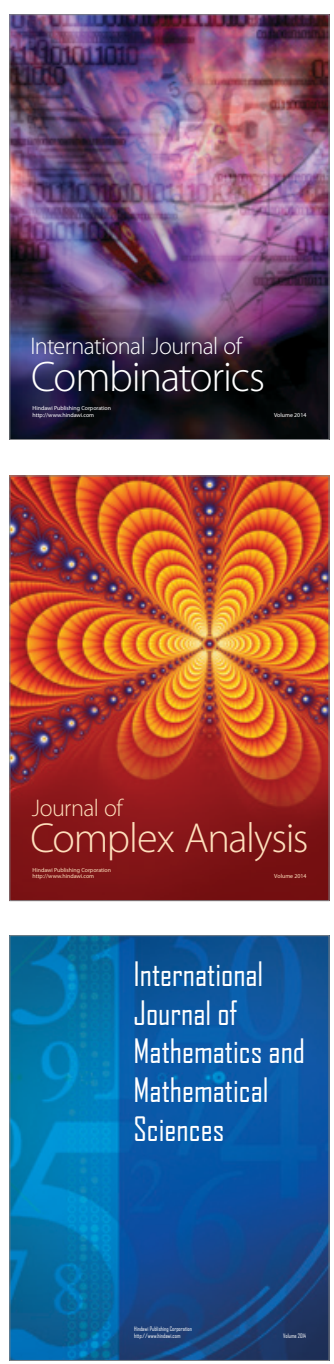
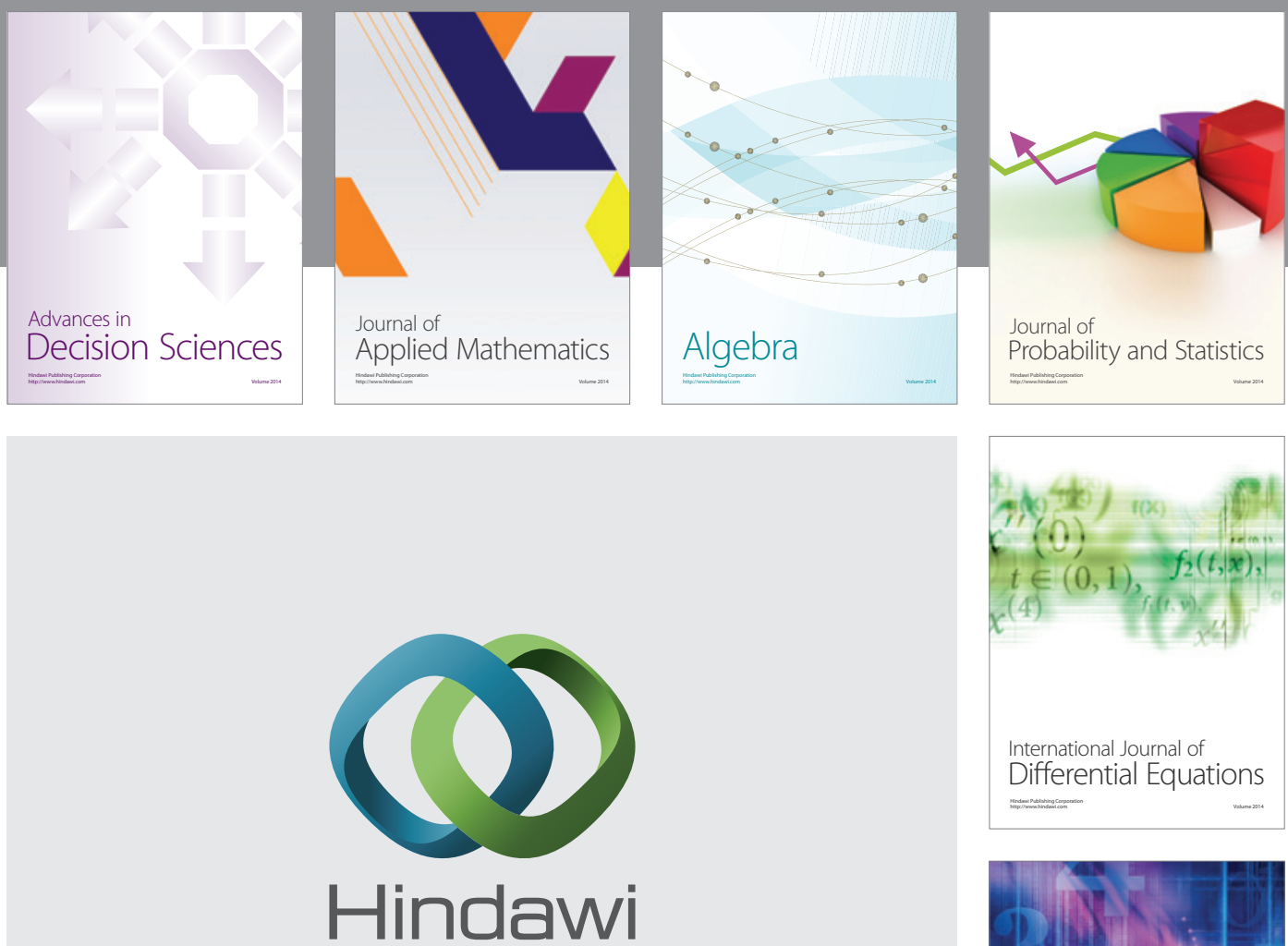

Submit your manuscripts at http://www.hindawi.com
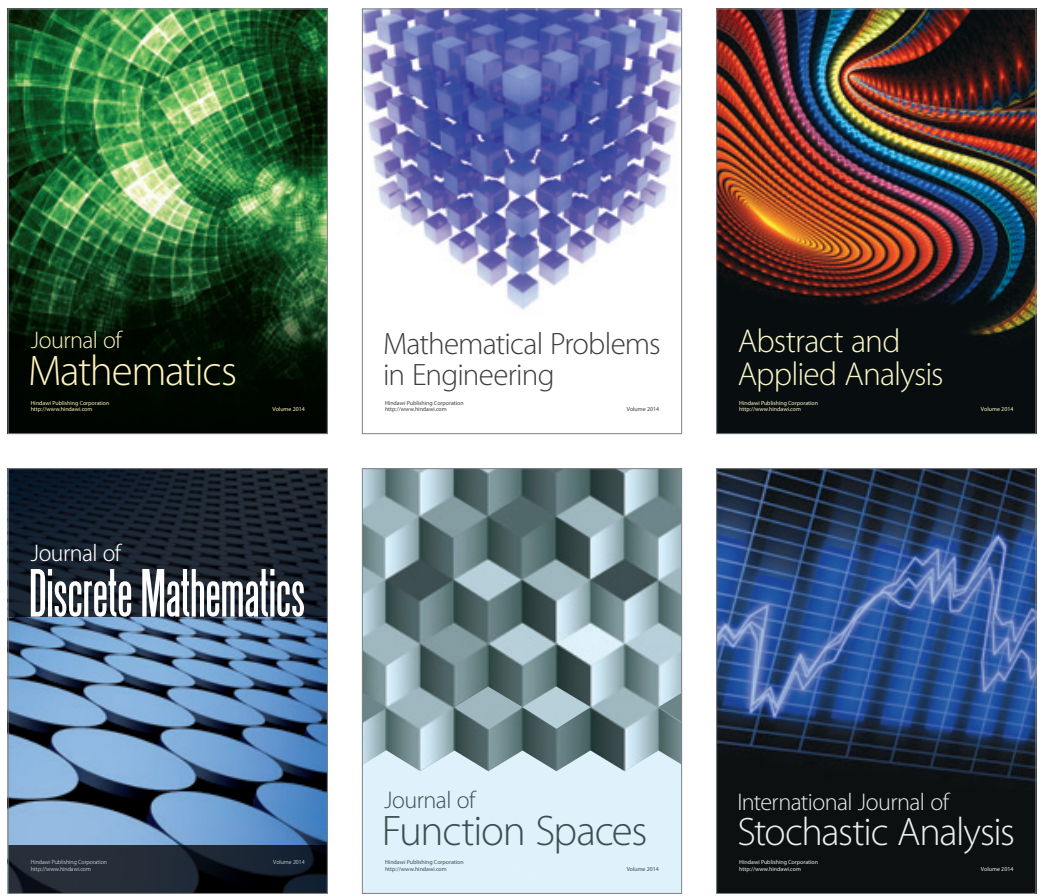

Journal of

Function Spaces

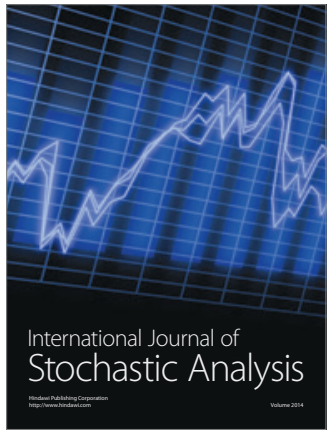

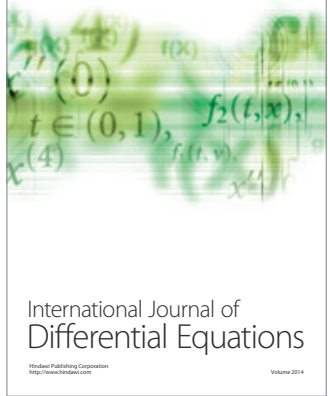
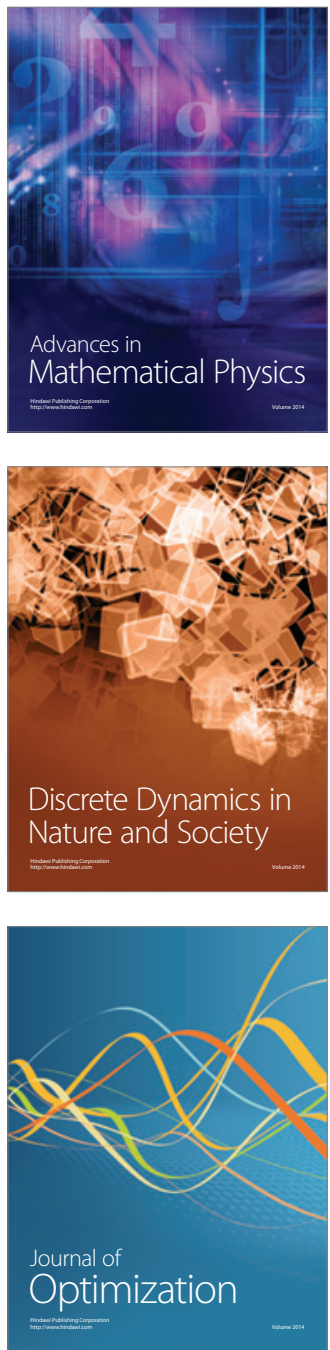